\title{
Effects of Back Muscle Strengthening Exercises in Patients with Chronic Non Specific Low Back Pain- A Clinical Trial
}

\author{
Rahman $\mathrm{MM}^{1}$, Rashid $\mathrm{MI}^{2}$, Shakoor $\mathrm{MA}^{3}$
}

\begin{abstract}
A randomized clinical trial was done to find out the effects of back muscle strengthening exercises in patients with chronic non specific low back pain (CNLBP). A total of 60 patients were included. They were divided into two groups, control group and interventional group by randomization with the way of lottery. Control group (Group-B) was treated with non steroidal anti inflammatory drugs (NSAIDs), activities of daily living (ADLs) instructions and warm moist compression. Experimental group (Group-A) was treated with NSAIDs), activities of daily living (ADLs) instructions, warm moist compression along with back muscle strengthening exercises. Initial evaluation and three follow up visits was given at two weeks, six weeks and twelve weeks. Measurement of pain intensity was performed by Visual Analogue scale (VAS). Student " $t$ " test and chi-square $\left(X^{2}\right)$ test was done to see the level of significance whenever it is necessary. A probability value ( $p$ ) of less than 0.05 was considered to indicate statistical significance. There was no significant improvement in pretreatment, after 2 weeks and after 6 weeks between two groups. But after 12 weeks follow up exercises group exhibited significant improvement than the control group $(P<0.001)$ So, it can be concluded that back muscle strengthening exercises is effective to improve the patients with CNLBP.
\end{abstract}

Key words: Exercises, low back pain,

\section{Introduction}

Low back pain is a substantial health problem. It affects up to $80 \%$ of the adult population and accounts for considerable health care and socioeconomic costs. ${ }^{1}$ Chronic back pain is the second most common reason why patients visit primary care physicians and is the number one cause of disability in men aged $31-45$. $^{2}$ Patients with chronic low back pain are frequently found in our day to day practice. LBP affects approximately $60-85 \%$ of adults during some points in their lives. Fortunately, for the large majority of individuals, symptoms are mild and transient, with $90 \%$ subsiding within 6 weeks. For the minority with intractable symptoms, the impact on quality of life and economic implications are considerable. ${ }^{3}$ There are various options for treatment

1. Corresponding Author: Dr. Md. Mahmudur Rahman FCPS Assistant Professor, Physical Medicine \& Rehabilitation Bangabandhu Sheikh Mujib Medical University, Dhaka E-mail: nilumahmud@gmail.com

2. Dr. Md. Imamur Rashid FCPS Medical Officer Physical Medicine \& Rehabilitation, Bangabandhu Sheikh Mujib Medical University, Dhaka

3. Dr. M A Shakoor FCPS Associate Professor, Physical Medicine \& Rehabilitation, Bangabandhu Sheikh Mujib Medical University, Dhaka of chronic low back pain. Of them pharmacotherapy and physical therapy (thermotherapy \& Exercise therapy) are commonly used. Exercise therapy remains one of the conservative mainstays of treatment for chronic low back pain and may be tailored to include aerobic exercise, muscle strengthening and stretching exercises. ${ }^{4}$ Significant variation in regimen, intensity and frequency of prescribed programs is the present challenges to assessing efficacy among patients. ${ }^{5}$ In this study an attempt has been made to find out the effects of back muscle strengthening exercises in the treatment of Chronic non specific low back pain and their outcome. The information thus gathered may provide useful guidelines for further study about various aspects on chronic non specific low back pain.

\section{Materials \& Methods}

The study was conducted in the Department of Physical Medicine \& Rehabilitation, Bangabandhu Sheikh Mujib Medical University, Shahbagh, Dhaka and Popular diagnostic centre, Uttara and Popular diagnostic centre, Narayangonj. Study population was all the patients of CNLBP attending in the outpatient department of physical medicine \& rehabilitation, during the study period. The patients were those suffering from low back pain for more than three months, irrespective of sex and between $30-70$ years of age. Meticulous history taking, clinical examination and relevant investigation were performed. Eligible participants were allocated into two groups, control group and experimental or interventional group by randomization with the help of lottery.

Control group was managed by non steroidal anti inflammatory drugs (NSAIDs), activities of daily living (ADLs) instruction and hot moist compression. Experimental group was receiving previous management along with back muscle strengthening exercises. Patients with acute low back pain, inflammatory low back pain, TB, malignancies and history of trauma over low back, uncontrolled diabetes mellitus, hypertension, asthma and heart diseases were excluded and patients during low back pain for more than three months were included in this study. Thus, the patients were divided into two groups. Group A consisted of patients who were treated with NSAIDs + Exercises + ADLs. + Hot moist compression. Group B patients were treated with NSAIDs + ADLs. + Hot moist compression. Initial evaluation and three follow up visits was given at two weeks, six weeks and twelve weeks by the same investigator. In each visit measurement of pain intensity and disability level was performed by Visual Analogue scale (VAS). Post intervention result was compared with baseline result. Data were processed manually and analyzed with the help of SPSS (Statistical package for social sciences) Version 19.0.Quantitative data were expressed as mean and standard deviation and comparison were done by student " $\mathrm{t}$ " test. Qualitative were expressed as frequency and percentage and 
comparison, carried by chi-square $\left(\mathrm{X}^{2}\right)$ test. Other statistical test was done whenever it is necessary. A probability value (p) of less than 0.05 was considered to indicate statistical significance.

\section{Results}

In group-A, the maximum patients were in $30-40$ years ( $53.3 \%$ ) of age group , $30 \%$ of the patients of age $41-50$ years, $10 \%$ of the patients of age 51-60 years, and $6.67 \%$ of the patients of 61-70 years were all allocated to group A. On the other hand, in Group-B, the maximum patients were in 30-40 years of age group (46.67\%), $26.67 \%$ of patients of age between $41-50$ years, $16.67 \%$ of patients of age between 51-60 years and $10.0 \%$ of the patients of age between $61-70$ years were allocated to Group-B ( Table-1).

Table-1: Age group distribution of the study group.

\begin{tabular}{cccc}
\hline \multirow{2}{*}{ Age group } & $\begin{array}{c}\text { Group-A } \\
\text { n (\%) }\end{array}$ & $\begin{array}{c}\text { Group-B } \\
\mathbf{n}(\%)\end{array}$ & \multirow{2}{*}{ Total } \\
\hline 30-40 yrs & $16(53.3)$ & $14(46.67)$ & 30 \\
41-50 yrs & $09(30.0)$ & $08(26.67)$ & 17 \\
$51-60$ yrs & $03(10.0)$ & $05(16.67)$ & 08 \\
$61-70$ yrs & $02(6.67)$ & $03(10.0)$ & 05 \\
\hline Total & $30(100)$ & $30(100)$ & 60 \\
\hline
\end{tabular}

$n=$ number of patients,$y r s=$ Years

The sex distribution of the present study was more or less same in both the group. That is in group-A $36.67 \%$ were male and $63.3 \%$ were female, in group-B $43.33 \%$ were male and $56.67 \%$ were female ( Table- 2 ).

Table- 2: Sex distribution of the study population

\begin{tabular}{cccc}
\hline \multirow{2}{*}{ Sex } & \multicolumn{2}{c}{ Study group } & \\
\cline { 2 - 3 } & $\begin{array}{c}\text { Group-A } \\
\mathbf{n ( \% )}\end{array}$ & $\begin{array}{c}\text { Group-B } \\
\mathbf{n}(\%)\end{array}$ & Total \\
\hline Male & $11(36.67)$ & $13(43.33)$ & $24(40 \%)$ \\
Female & $19(63.3)$ & $17(56.67)$ & $36(60 \%)$ \\
\hline Total & $30(100)$ & $30(100)$ & $60(100 \%)$ \\
\hline
\end{tabular}

$n=$ number of patients

Regarding improvement after treatment, it was found that in pre treatment mean Visual Analogue Scale Score was $7.10( \pm 1.32)$ were in group A and $27.30( \pm 1.11)$ were in group B ( $>>0.05)$, after 2 weeks follow up $5.30( \pm 1.29)$ were in group $A$ and $5.60( \pm 1.13)$ were in group $\mathrm{B},(\mathrm{P}>05)$ which was not significant and after 6 weeks follow up $2.50( \pm 1.13)$ were in group A and $3.00( \pm 1.43)$ were in group $B(p>0.05)$ that was not statistically significant. But after 12 weeks follow up the score was $0.20( \pm 0.40)$ in group A and $1.10( \pm 0.71)$ was in Group B $(\mathrm{p}<0.05)$ that was statistically significant (Table 3$)$. This indicates that exercise is beneficial to improve CNSLBP.
Table 3: Mean Visual Analogue Scale Score pretreatment and 2 weeks, 6 weeks and 12 weeks follow up.

\begin{tabular}{cccc}
\hline & \multicolumn{2}{c}{ Study group } & \\
\cline { 2 - 3 } $\begin{array}{c}\text { Visual Analogue } \\
\text { scale }\end{array}$ & $\begin{array}{c}\text { Group A } \\
\text { Mean( } \pm \text { SD })\end{array}$ & $\begin{array}{c}\text { Group B } \\
\text { Mean }( \pm \text { SD })\end{array}$ & P value \\
\hline $\begin{array}{c}\text { Pretreatment } \\
\text { Score }\end{array}$ & $7.10( \pm 1.32)$ & $7.30( \pm 1.11)$ & $1.00^{\mathrm{ns}}$ \\
$\begin{array}{c}\text { Score at W2 } \\
\text { Score at W6 }\end{array}$ & $5.30( \pm 1.29)$ & $5.60( \pm 1.13)$ & $0.42^{\mathrm{ns}}$ \\
Score at W12 & $0.20( \pm 0.40)$ & $1.10( \pm 0.71)$ & $<0.001^{\mathrm{s}}$ \\
\hline
\end{tabular}

$\mathrm{NS}=$ Not significant, $\mathrm{S}=$ Significant, $\mathrm{SD}=$ Standard Deviation , W2 $=$ two weeks, W6 $=$ Six weeks, W12 = twelve weeks

\section{Discussion}

Finding showed that male female ratio in the present study was $1: 1.5$. However, the difference was not significant $(\mathrm{P}>0.05)$ between the two groups. Similarly, Mathur et al. ${ }^{6}$ found male predominance where the authors found male to female ratio was $1.1: 1$. In another study Borman et al. ${ }^{7}$ found male to female ratio was 1:1.6 and 1:2.5 in group A and group B respectively. But in large epidemiological studies no statistically significant difference exists between the male and female. Shakoor et al. ${ }^{8}$ in a study conducted with 102 patients of chronic low back pain in BSMMU from April 2012 to March 2013 found that male-female ratio was $1: 1.43$. These findings are consistent with this study. However, the female preponderance found in this study may be due to more female attendance in the hospital than male. As the male patients remain busy with their works during hospital outdoor service period, they usually consult with doctors in the evening.

The improvement in the patients in the present study may be explained by the effect of therapeutic exercise. Exercise is one of the most important rehabilitation modalities. 9,10 In this study, patients who continued with exercises had better improvement in disability and pain scores. ${ }^{9}$ Exercise may have a significant role in clinical improvement. ${ }^{9}$ McKenzie suggested extension exercises and Hansen et al. ${ }^{10}$ applied a method based on principles used in body building which involve intensive dynamic hyper-extension back exercises. These exercises were reported to be beneficial in the treatment of patients with chronic low back pain. The improvement of this study in both groups may also be explained by physical therapy consisting of local superficial heat and thermal ultrasound effects, a proposed mechanism of alleviating pain. But most of the previous studies indicated temporary efficacy of these modalities. ${ }^{11,12}$

The mean pain score was not statistically lower at follow-up, while the disability scores reduced, indicating improvement on disability but no statistically significant improvement seen. In this study, patients reported feeling better as a result of therapeutic exercise, but they still experienced recurrence of pain at follow-up. Perhaps other factors such as psychosocial 
or environmental factors not assigned in this study may have an effect on perceiving chronic pain obtained by Nickel et al. ${ }^{13}$

By the present study it can be concluded that back muscle strengthening exercises seemed to improve the patients with CNLBP.

\section{Reference}

1. Wand BM, Oconnell NE. Chronic non-specific low back pain subgroups or a single mechanism? BMC, Musculoskeletal Disorders 2008,9:11

dio:101186/1471-2474-9-71-2474-9-11

2. Bacon NMK, Bacon SF, Atkinson JH, Slater MA. Somatization symptoms in chronic low back pain patients, Psychosomatic Medicine, 1994;56:118-127

3. Kimberley M, David EF, Lumber spondylosis: Clinical presentation and treatment approaches. Current review musculoskeletal Med. 2009;2:94-104

4. Hayden JA, Tudler MW, Tomolinson G, Systemic review; strategies for using exercise therapy to improve outcomes in chronic low back pain. Ann Intern Med. 2005;142:776-85.

5. Shipley M, Black CM, Denton CP, Compston J and O' Gradaigh d. Rheumatology and bone disease. In Kumar P, Clark M (editors) Kumar and Clark Clinical Medicine, $6^{\text {th }}$ ed. Elsevier: saunders, 2005;540-541

6. Mathur HH, Chaudhary D, Mathur D, Patki PS and Mitra SK Evaluation of the clinical efficacy and long-term safety of Rumalalya forte tables and Rumalaya liniment in patients suffering from lumbago associated with lumbar arthrosis (spondylosis): An open study. Indian Medical journal 2009;103:57-60.

7. Borman P, Keskin D, Bodur H. The efficacy of lumber traction in the management of patients with low back pain. 2003;23:82-6

8. Shakoor MA, Rahman MS, Moyeenuzzaman M. Effect of deep heat therapy on the patients with chronic low back pain. Mymensing Med J 2008;117:32-38.

9. Revel M. Does traction still have a role in nonspecific low back disorders. Joint Bone Spine 2000;67:146-149

10. Hansen FR, Bendix T, Skov P, Jensen CV, Kristanse $\mathrm{JH}$ et al. Intensive dynamic back muscle exercises, conventional physiotherapy or placebo control treatment of low back pain. Spine 1993;18:98107.

11. Li LC, Bombardier LLC. Physical therapy management of low back pain, An explanatory survey of therapist approaches. Physical Ther 2001; $81: 1018-1027$

12. Gherkin DJ, Deyo RA, Wheeler K, Ciol MA. Physician views about treating low back pain. Spine 1995;20:1-10,

13. Nickel R, Egle UT, Eysel P, Rompe JD, Zollner J, Hoffmann SO. Health-related quality of life and somatization in patients with long-term low back pain. Spine 2001;26:2271-2277. 